\title{
“A arte do evento": acidente, narrativa e forma em La Glace à trois faces, entre Jean Epstein e Paul Morand
}

\author{
José Bértolo \\ Centro de Estudos Comparatistas, Faculdade de Letras da Universidade de Lisboa
}

Resumo: Neste ensaio, atenta-se no modo como, em La Glace à trois faces (1927), Jean Epstein se apropria da complexa estrutura do conto homónimo de Paul Morand para desenvolver uma investigação sobre algumas questões relacionadas com o cinema, em particular com a narrativa cinematográfica. Convocando dois ensaios da autoria do cineasta, cuja publicação acompanhou a estreia do filme, e analisando algumas das sequências cruciais deste, argumenta-se que Epstein trabalha o motivo do acidente (no caso, um acidente de automóvel) de forma a propor uma ideia de cinema enquanto "arte do evento".

Palavras-chave: Cinema e Literatura, Cinema Francês, Jean Epstein, Paul Morand, Primeira Vanguarda Francesa

\begin{abstract}
In this essay, I consider the ways in which, in La Glace à trois faces (1927), Jean Epstein puts to work the complex structure of Paul Morand's homonymous short story in order to investigate on some questions related to cinema as medium, and particularly on cinematographic narrative. Discussing two essays by the filmmaker which were published in the same year La Glace à trois faces was first screened, and analyzing crucial sequences of the film, I will then argue that Epstein uses the motif of the accident (in this case, an automobile accident) in a way that enables him to meditate on cinema as an "art of the event".
\end{abstract}

Keywords: Film and Literature; First French New Wave; French Cinema; Jean Epstein; Paul Morand 
Os críticos tendem a dividir a obra de Jean Epstein em grupos correspondentes a diferentes estágios da sua carreira. A distinção mais frequente é feita entre duas grandes fases, a primeira terminando com La Chute de la maison Usher (1928), e a segunda começando com Finis Terrae (1929) e culminando no seu último filme, Les Feux de la mer (1948). É notório que, até La Chute, os filmes realizados por Epstein partilham uma série de características com o trabalho de outros cineastas associados à Primeira Vanguarda Francesa da década de 1920, tais como Marcel L'Herbier, Louis Delluc ou Abel Gance. Este é um conjunto de artistas que, não obstante vincadamente heterogéneo, aspira a libertar o cinema das influências do teatro e da literatura, criando uma nova linguagem cinematográfica através, sobretudo, do trabalho sobre a forma e a narrativa. Porém, para realizar Finis Terrae, Epstein abandona os estúdios de Paris e torna a sua atenção criativa para os espaços naturais e as gentes da Bretanha, passando a filmar a linha costeira, o mar, as populações locais e as suas lutas, num estilo que pode ser entendido como, em alguns aspectos (não-actores, espaços naturais, uma certa dimensão social), precursor do Neorealismo italiano que surgiria muito mais tarde, na década de 1940.

De acordo com esta divisão operativa, La Glace à trois faces insere-se na primeira fase da obra de Epstein, quando este ainda segue o estilo e a ideologia daquilo que Henri Langlois classifica como o Impressionismo [cinematográfico] francês (cf. nota 2). Para além de se situar nessa primeira fase, esta obra integra ainda um subgrupo de filmes constituído pelos três últimos assinados por Epstein antes da partida para a Bretanha, designadamente Six et demi onze (1927), o mesmo La Glace à trois faces e La Chute de la maison Usher. É possível dizer-se que estes filmes constituem um ciclo autónomo, uma vez que eles partilham, entre outras características, dois aspectos importantes no que diz respeito às condições de produção, aos temas e ao estilo. Em primeiro lugar, eles são financiados pela companhia fundada por Epstein, Les Films Jean Epstein, que garante ao cineasta o controlo absoluto sobre a produção dos filmes. ${ }^{1}$ Em segundo lugar, estas três obras formam um grupo particularmente coeso, tal como propôs Christophe Wall-Romana, ao discutir La Glace: "[La Glace à trois faces] represents the middle panel of a triptych addressing representations of the human face on three visual supports - photography, mirror, 
"A arte do evento": acidente, narrativa e forma em La Glace à trois faces, entre Jean Epstein e Paul Morand

painting - each of which accentuates a particular aspect of cinema" (Wall-Romana 2013: 77). De acordo com a leitura do crítico, estes são filmes eminentemente auto-reflexivos, constituindo uma meditação sobre a psique humana, mas também sobre o cinema como meio de representação, e sobre o mundo físico (o real) na relação com, e contra, o qual o cinema se define. Esta imanência teórica e filosófico-especulativa é, no entanto, característica da generalidade da obra de Epstein, dado que entre os diversos cineastas da Primeira Vanguarda, o cineasta de origem polaca desempenha justamente o papel de "cineasta-filósofo", tal como avança Robert Sinnerbrink:

The appearance of both avant-garde cinema and cinematic artist-auteurs during the 1920s saw a more speculative film-philosophy emerging, brilliantly articulated by Jean Epstein, one in which it was no longer philosophical speculation or aesthetic theory but cinema itself that was expressing the "thinking”. (Sinnerbrink 2013: ๆ4)

De entre os três filmes referidos, Six et demi onze parece ser o que, com a sua narrativa linear e melodramática, melhor corresponde a uma narrativa clássica, tornandose, por conseguinte, aquele com mais apelo comercial. Contudo, o filme fracassa junto do público, razão pela qual Epstein concebe o filme seguinte, La Glace, visando deliberadamente o circuito alternativo de filmes com um cariz mais vanguardista ou experimental, no que Richard Abel descreveu como uma decisão artística notoriamente radical da parte do realizador:

At first, La Glace à trois faces (1927) may seem to mark a change in Epstein's work. As far as I can tell, it premiered at the Studio des Ursulines, in November, 1927, and then was distributed within the circuit of specialized cinemas and ciné-clubs in France, Belgium, Switzerland, and England. This makes it [...] one of the first narrative films produced exclusively for the alternate cinema network that had originated in France and spread across Europe. (Abel 1984: 456)

De certo modo, La Glace pode ser considerado o filme mais experimental de uma das fases mais experimentais da carreira de Epstein, e no estabelecimento desta posição, ainda mais do que em La Chute de la maison Usher (que se tornaria o filme paradigmático desta 
primeira fase da filmografia do cineasta), a estrutura narrativa do filme desempenha um papel fundamental. Abel classifica-a como "the most complicated film structure of the decade" (Abel 1984: 456), e outros críticos intuem nela o prenúncio do que viria a ser uma tipologia particular de cinema, que surgiria na década de 1960, auxiliada pelo advento do nouveau roman. Estes críticos declaram que La Glace é um "predecessor do cinema moderno, particularmente de filmes como L'Année dernière a Marienbad [1961] e, especialmente, Je t'aime je t'aime [1968]" (Vichi 2002: 104, tradução minha). Tal como estas duas obras realizadas por Alain Resnais, o filme de Epstein é notável no modo como desenvolve simultaneamente uma reflexão sobre a narrativa e sobre o tempo em cinema.

Nas páginas seguintes, atento no modo como Jean Epstein toma do conto homónimo de Paul Morand a sua complexa estrutura narrativa, usando-a como ponto de partida para uma investigação mais ampla, centrada em algumas questões especificamente cinematográficas, que o realizador considera encontrarem-se entre as mais importantes e singulares desta arte. Em suma, é minha intenção compreender por que razão neste filme "le cadre formel [est] exactement adapté au sujet" (Daire 2014: 89). No seguimento da minha inquirição, procuro ainda demonstrar como o filme de Epstein ilustra adequadamente a ideia que René Audet avança num ensaio sobre obras literárias que se constroem sobre o princípio da heterogeneidade, segundo a qual, por vezes, a natureza "diffracted" do objecto "represent[s] a world in which unity is lacking" (Audet 2014: 43). Por fim, proponho uma unidade formal para La Glace à trois faces, consubstanciando a minha hipótese com alguns escritos do próprio Epstein. Tomando em consideração o seu célebre artigo "Art d'événement", que é escrito e publicado ao mesmo tempo que La Glace estreia, argumento finalmente que o acidente que ocorre perto da conclusão do filme é o elemento que articula todas estas questões, ultimando a sua forma. 
"A arte do evento": acidente, narrativa e forma em La Glace à trois faces, entre Jean Epstein e Paul Morand

\title{
I. Contar histórias: Morand e Epstein
}

\author{
Comment peut-on être le même homme en \\ étant décrit de façon si contradictoire par \\ trois femmes?
}

Philippe Sollers, La Guerre du Goût

Diversos críticos aproximam La Glace à trois faces, de Epstein, ao universo do escritor italiano Luigi Pirandello. Laura Vichi, por exemplo, identifica uma "estrutura pirandelliana" (Vichi 2002: 109) e Régis Labourdette aponta para a "nota pirandelliana" (Labourdette 1998: 187) que, na sua perspectiva, o filme de Epstein contém. Também Abel se refere à "highly original, Pirandellian narrative structure (remarked on at the time), both on the general level of relations between the separate stories and on the specific level of syntactical and rhetorical relations within and between sequences" (Abel 1984: 456), mas é curioso notar que, quando o crítico explica por que razões a estrutura do filme de Epstein é "pirandelliana", ele descreve uma estrutura que é, na verdade, muito próxima do conto originalmente escrito por Paul Morand, também intitulado "La Glace à trois faces", e que inaugura o volume de contos L'Europe galante (1925). Não obstante este facto, pode ser efectivamente pertinente reconhecer Pirandello como um autor próximo de Morand, de modo a sublinhar o facto de que, ao adaptar este texto, Epstein está finalmente a tornar a sua atenção para o século XX, e em particular para a literatura modernista, depois de ter adaptado Balzac em L'Auberge rouge (1925) e George Sand em Mauprat.

A literatura é uma parte importante da vida de Epstein, que inicia a sua carreira enquanto escritor com La Poèsie d'aujourd'hui : un nouvel état d'intelligence (1921), no qual escreve sobre literatura contemporânea, seguindo-se a este primeiro livro La Lyrosophie (1922). Stuart Liebman defende inclusivamente que estes primeiros ensaios sobre literatura "ought to be closely examined because they [constitute] the basis for [Epstein's] earliest theoretical speculations about film" (Liebman 2012: 74), realçando a sua importância para o adequado entendimento da produção teórica e cinematográfica do cineasta. Em La Glace à trois faces, Epstein conjuga finalmente as suas reflexões sobre o cinema como arte da modernidade (é este o tema do seu primeiro livro sobre cinema, 
também de 1921, Bonjour cinéma) e as suas ideias sobre literatura moderna, de modo a criar uma reflexão simultaneamente sobre o cinema, a literatura e a experiência do homem moderno, e criando deste modo "one of the most modernist of films within the impressionist ${ }^{2}$ tradition" (Aitken 2001: 77).

Antes de me centrar na análise do filme, e uma vez que a sua "complicada" (Abel) estrutura narrativa é muito próxima daquela que encontramos no conto de Morand, detenho-me brevemente no texto.

O conto de cerca de dez páginas divide-se em quatro partes numeradas. A parte I principia com um parágrafo em itálico, no qual o narrador intradiegético recorda um dia em que se encontrava num "petit salon" (Morand 2000: 9) com uma mulher de nome Pearl. Um espaço em branco separa este primeiro bloco de texto de um segundo inteiramente constituído por linhas de diálogo que correspondem à conversa mantida pelo narrador e por Pearl, durante a qual esta fala sobre um seu amante, sem em algum momento o nomear. A parte II começa com um novo segmento textual em itálico e entre aspas, ao fim do qual se lê a assinatura "PENCIL", e em que é descrita uma escultora, Mlle Athalia Roubinovitch. No segundo bloco de texto, o narrador esclarece o leitor, contando que o segmento anterior era uma “interview-express' d'un quotidien mondain" (Morand 2000: 13), e procede para a sua própria descrição da mulher e para a transcrição de uma conversa que teve com ela, durante a qual esta lhe falou sobre o seu amante, sem que - tal como acontecera no segmento anterior - forneça o seu nome em algum momento.

A parte III contém apenas um bloco de texto, que inicia com o narrador a reportar-se a Lucie, uma rapariga pobre, e que prossegue para a transcrição de outra conversa tida entre o narrador e Lucia, durante a qual, novamente, a mulher fala de um homem sem nome com quem mantém um relacionamento problemático.

A parte IV, intitulada "Épilogue", é muito breve e, por ser fundamental para a compreensão do conto, transcrevo-a na íntegra:

Il avait été mon ami. Je ne l'avais plus revu dépuis des années.

Je le trouvai, ce matin de décembre, couché sur un des côtés de la route des Quarante-Sous. Un martinet qui volait bas était venu le frapper, comme une pierre, entre les deus yeux. A cent trente à l'heure il avait 
"A arte do evento": acidente, narrativa e forma em La Glace à trois faces, entre Jean Epstein e Paul Morand

perdu connaissance et lâché son volant. Maintenant il se mourait. Son sang abondant se perdait dans la terre noire des labours d'automne, car le pare-brise lui avait ouvert la gorge. Avant d'expirer, il me pria, d'une voix courie, d'aller annoncer la nouvelle aux trois noms qu'il me donna : c'étaient ceux de Pearl, d'Athalia et de Lucie.

Ainsi j'appris d'un coup que ces aveus reçus de trois femmes ne cachaient qu'un homme et que cet homme c'était lui. A ces trois airs chantés dans le vide, un même ténor répondait ; plaintes si diverses qu'il les fallait plutôt penser adressées à divers amants, les plus dissemblables, qu'à un seul.

Aujourd'hui encore, au souvenir de ces récits, il m'arrive de croire que j'ai eu trois amis et qu'ils ont été tués tous trois par une hirondelle. (Morand 2000: 18, ênfase no original)

A natureza experimental da narrativa é notória em diversos aspectos. A divisão em capítulos curtos num conto breve agudiza a sua fragmentariedade, e a coexistência de texto em itálico e sem ênfase gráfica inscreve no relato uma heterogeneidade desde logo visível. 0 recurso à peça de jornal no início da parte II, bem como a alternância entre os modos descritivo e narrativo, também sublinham a natureza compósita do texto. A situação narrativa em que três personagens diferentes falam ao mesmo narrador sobre um terceiro homem acentua a insuficiência da percepção humana face à natureza multifacetada do real, revelando que existem tantas versões de uma dada situação (ou, neste caso, de um indivíduo) quanto pessoas existem para partilhar o seu ponto de vista. Consequentemente, o conto oferece uma meditação sobre a identidade humana, e em particular, nos termos de Wall-Romana, sobre a "postmodern recognition of our reliance on others for social identity" (Wall-Romana 2013: 78), o que se relaciona aqui, directamente, com a estrutura narrativa, tal como sugere Vichi quando afirma que "esta fragmentação total [...] responde à identidade indecidível da personagem masculina" (Vichi 2002, 105, tradução minha). Oferecendo ao leitor um acesso indirecto ao homem desconhecido, através das palavras de três mulheres, Morand sugere que a identidade é - tal como o texto - fragmentada e heterogénea, e que apenas na morte é possível atingir alguma espécie de unidade e de conhecimento. Este movimento terá, argumentarei adiante, implicações decisivas na economia do filme.

A estrutura narrativa de La Glace à trois faces é semelhante à do texto de Morand. 0

N. 41 - 12/ 2019 | 13-35 - ISSN 2183-2242 | http:/dx.doi.org/10.21747/21832242/litcomp41a1

19 
filme começa com um intertítulo em que se lê: "Trois femmes aimaient un homme. Mais lui en aimait il une ?". Este intertítulo inscreve no filme uma nota de mistério que já marcava presença na história de Morand, onde, no final da primeira parte, o narrador diz a Pearl: "Je serais curieux d'apprendre son nom" (Morand 2000: 12). Quando ela recusa revelar o nome, ele reforça a sua curiosidade com uma nova pergunta: "Le connais-je ?" (Morand 2000: 12). A questão, no conto, poderia ser, então: “quem é o homem de que falam estas mulheres?" Se a questão com que o filme começa é outra, torna-se, no entanto, relevante notar que Epstein inicia o filme num modo interrogativo. Ao mostrar a pergunta antes do intertítulo inicial no qual podemos ler "I" [primeira parte], e, portanto, fora da estrutura quadripartida do filme, o cineasta subjuga todas as quatro partes a esta pergunta inaugural. Deste modo, ele apresenta o seu filme como um objecto dinâmico que coloca questões e oferece diversas possibilidades de resposta, desafiando o espectador a procurar um sentido para o filme.

Após o primeiro intertítulo, o filme divide-se em quatro segmentos, três deles numerados e intitulados de acordo com os episódios correspondentes na história de Morand (Pearl, Athalia e Lucie) e um último correspondente ao homem, "Lui” [Ele]. Em cada uma destas secções vemos uma mulher contar a outros homens a sua relação difícil com "Lui". A primeira diferença entre o texto e o filme prende-se com o facto de, em Morand, as três mulheres contarem a história ao mesmo homem (o narrador), e, em Epstein, elas falarem com diferentes homens que não possuem qualquer relevância no filme para além de serem os confidentes anónimos e emudecidos destas mulheres. O narrador é uma figura essencial em Morand porque ele é ao mesmo tempo uma figura representativa do escritor - na medida em que ele é o coleccionador de três narrativas que partilha com o leitor, dando origem ao texto de Morand - e do leitor, pois enquanto ele ouve as histórias das mulheres procura interpretá-las, visando descobrir a identidade do misterioso protagonista. No filme, porém, esta personagem é omitida e substituída pelos três interlocutores e pelos relativamente escassos intertítulos que acompanham o fluxo das imagens.

Um aspecto singular do filme é que, enquanto as mulheres contam as suas histórias 
aos seus amigos, as situações narradas são mostradas ao espectador. Este mecanismo desencadeia uma multiplicidade de níveis diegéticos que recupera uma tradição literária que remonta a obras como Il Decameron, de Giovanni Boccaccio (1351), ou The Canterbury Tales, de Geoffrey Chaucer (1478), nos quais o primeiro nível da acção é interrompido de cada vez que uma personagem narra uma história, a qual, por sua vez, passa para primeiro plano. Este reajuste é motivado pela capacidade do cinema de - sendo primariamente um meio visual - mostrar e não apenas contar histórias, e consiste, por isso, na maior "infidelidade" em relação ao conto, onde a voz das narradoras é a substância da qual são feitas as histórias. Em Morand, o leitor não tem acesso algum a "Lui", para além dos actos de fala que o deslocam como um pronome nominalizado, e o transformam numa paradigmática "figura da ausência" (Vernet 1988), um referente vazio em torno do qual a narrativa é construída. No filme, por seu turno, quando nos são mostradas as "dramatizações" das narrativas das mulheres, ${ }^{3}$ vemos "Lui" a ser interpretado por René Ferté, dotado de uma inegável corporealidade cinematográfica.

Assim, e simultaneamente, Epstein reconfigura a tradição da "narrativa enquadrada" em contexto modernista e também o "filme por episódios" que remonta a Intolerance, de D. W. Griffith (1916), e que viria a ser crucial nos novos cinemas das décadas de 1960 e 1970, constituindo as variações de Pasolini sobre Boccaccio, Chaucer e As Mil e Uma Noites os exemplos mais proeminentes. Como filme episódico, contudo, La Glace parece ser um exemplo ainda mais ousado do que a maior parte dos seus pares, especialmente porque as histórias dentro da história interligam-se com outra misteriosa situação que escapa a estes dois níveis elementares (isto é, o tempo presente da narração e os tempos passados das histórias). Esta situação é adequadamente descrita por Malcolm Turvey, ao escrever que "[i]ntercut with [the three women's] reminiscences are shots of Him ["Lui"] retrieving his sports car from a garage and driving through towns from where he sends messages, one at a time, to each of the three women, informing them that he will not be joining them" (Turvey 2008: 51-2).

Comecei esta secção por fazer notar que a estrutura de La Glace à trois faces provém directamente do conto de Paul Morand, descrevendo brevemente ambas e identificando 
alguns elementos que o conto e o filme partilham, tal como outros em que eles divergem. Porém, ainda não contemplei as razões que poderão ter levado Epstein a escolher adaptar uma narrativa breve com características singulares, tais como: 1) depender de um esquema textual compósito; 2) encenar uma tensão significativa entre as diferentes partes e o todo; 3) propor um pensamento sobre a percepção e o ser; e 4) usar a figura do acidente como o evento culminante da história. Na secção seguinte, procuro compreender de que modo Epstein usa o conto de Morand com vista a explorar questões teóricas que, residindo já no texto de base, são expandidas pelo cineasta no filme e adaptadas à especificidade da arte cinematográfica.

\section{Estilo e narrativa: a procura da forma}

Oserait-on dire que le monde est peuplé de correspondances inconnues, d'allusions vivantes, d'invisibles symétries ? Nos actes ont-ils double face? Ou ne sont-ils que réfraction, comme ces rayons qui, traversant certains cristaux, se divisent en deux?

Paul Morand, "Écho, répondez"

Fiz notar que a estrutura narrativa de La Glace à trois faces é notoriamente múltipla. No entanto, Epstein tornou-se reconhecido nos últimos anos precisamente pela sua suposta rejeição da narrativa em cinema. Isto teve lugar após a publicação de La Fable cinématogaphique, de Jacques Rancière, em 2001. Na célebre abertura desse ensaio, o filósofo francês cita Bonjour cinéma, de Epstein:

Généralement, le cinéma rend mal l'anecdote. Et "action dramatique" y est erreur. Le drame qui agit est déjà à moitié résolu et roule sur la pente curative de la crise. La véritable tragédie est en suspens. [...] Elle se dissout dans le verre d'eau. Toute la chambre se sature de drame à tous les stades. Le cigare fume comme une menace sur la gorge du cendrier [...] Le cinéma est vrai. Une histoire est un mensonge. (Epstein apud Rancière 2001: $7^{4}$ ) 
"A arte do evento": acidente, narrativa e forma em La Glace à trois faces, entre Jean Epstein e Paul Morand

Afirmar categoricamente que Epstein rejeita a narrativa consiste, no entanto, numa tresleitura destas linhas. É necessário tomar em consideração que quando Bonjour cinéma é escrito, em 1921, a década de 1910 acaba de terminar, sendo esta uma década particularmente decisiva na história do cinema por assistir à afirmação de cineastas como D.W. Griffith nos Estados Unidos da América, Victor Sjöström na Suécia, ou Louis Feuillade em França, que procuram legitimar o cinema enquanto forma de arte após este ter sido desconsiderado como pouco mais do que um divertimento ao longo dos anos 1890 e 1900. De forma a levar a cabo esta legitimação, estes e outros cineastas aproximam o cinema das artes veteranas, em particular a literatura e o teatro, que contribuem, assim, para estabelecer a narratividade como elemento essencial à prática cinematográfica, contra a componente mais situacional do "cinema das atracções" (a expressão é de Tom Gunning) dos primeiros quinze anos.

Na década de 1920, o cinema narrativo dos anos 1910 é - não obstante muitas vezes admirado (como é o caso dos três realizadores que referi como exemplos) considerado convencional pelos novos cineastas, e é neste contexto que se deve entender as afirmações de Epstein. Na passagem citada, ele não está, de facto, a desconsiderar inteiramente a narrativa em filme, mas afirmando que, na sua particular proximidade à realidade e à vida, o cinema não precisa necessariamente de criar histórias (fables) porque estas "contredi[sent] la vie qu'elle[s] prétend[end] imiter", pois, na verdade, "[l]a vie ne connaît pas d'histoires. Elle ne connaît pas d'actions orientées vers des fins, mais seulement des situations ouvertes dans toutes les directions" (Rancière 2001: 8). Em suma, e isto é algo que Rancière reconhece em termos aristotélicos, Epstein está a favorecer a opsis em relação ao muthos, ou, melhor ainda, a pôr o muthos ao serviço da opsis, que é o oposto do que, na perspectiva dos realizadores de vanguarda dos anos 1920, sucedera numa parte substancial dos filmes produzidos na década precedente.

Esta é uma característica fulcral da Primeira Vanguarda Francesa. Tal como afirma Richard Abel - e à excepção de alguns filmes de Germaine Dulac, que, a partir de dado momento, passa a postular a ideia de um "cinéma pur", abstracto e não-narrativo —, os filmes realizados por estes cineastas é sobretudo narrativo, sendo esta a razão pela qual 
Abel prefere "French Narrative Avant-garde" às outras terminologias (cf. nota 2). Porém, estes realizadores franceses usam a narrativa como um pretexto para experimentar com a forma. Quando El Dorado (1921), de L'Herbier, é criticado devido à "banalité moins que mélodramatique de ses sujets" (Canudo 2003: 142), o cineasta responde do seguinte modo: “Ce n'était pas par le sujet que j'entendais ennoblir mon film mais par la façon que j'aurais de composer ses images et de les orchestrer" (L'Herbier 1998: 56). Podemos também lembrar, por exemplo, que apenas um ano antes de La Glace, Dimitri Kirsanoff realiza Ménilmontant (1926), o primeiro filme francês que, inspirado nos Kammerspielfilme alemães (Scherben [1921], de Lupu Pick, ou Der Letzte Mann [1924], de F.W. Murnau, ambos com argumento de Carl Mayer), sendo indubitavelmente narrativo, não contém, no entanto, um único intertítulo.

Epstein está sintonizado com L'Herbier e Kirsanoff, na medida em que também ele instrumentaliza a narrativa ao serviço de outros focos de interesse. No entanto, se pode haver alguma base que sustente a visão que Canudo tem de L'Herbier enquanto um decorativista ou um formalista, as experimentações formais de Epstein são substancialmente guiadas pelas suas investigações teóricas e filosóficas, que tornam $\mathrm{La}$ Glace à trois faces, necessariamente, algo mais do que uma mera experiência formal. ${ }^{5}$

Afirmei antes que La Glace à trois faces se destaca na filmografia de Epstein pelas suas qualidades formais e teóricas. Na verdade, diversos autores consideram-no o auge do trabalho cinematográfico desenvolvido por Epstein nos anos 1920 e, até, de todo o cinema produzido em França durante essa década. Na primeira monografia dedicada a Epstein, Pierre Leprohon considera que “[l]'œuvre est capitale, non seulement dans la carrière de l'auteur, mais dans l'évolution même du style du récit visuel, elle apportait un total bouleversement" (Leprohon 1964: 43). Richard Abel também afirma que "La Glace à trois faces represents a culmination of much of the narrative avant-garde film practice" (Abel 1984: 456) e, de forma particularmente eloquente, Vichi afirma que:

O filme é apresentado como um "filme-ensaio" que, por um lado, resulta da investigação desenvolvida por Epstein até então, e, por outro lado, expressa ideias teóricas que o realizador desenvolveria no 
"A arte do evento": acidente, narrativa e forma em La Glace à trois faces, entre Jean Epstein e Paul Morand

curso da sua carreira, particularmente no que diz respeito à sua reflexão sobre o tempo. (Vichi 2002: 104, tradução minha)

O filme também pode ser visto, a um nível algo superficial mas ainda assim digno de relevo, como uma variação sobre géneros e estilos de representação, que incluem topoi do melodrama convencional no primeiro e no segundo segmentos, a representação pitoresca da natureza e o comentário social no terceiro segmento, a estética da velocidade característica do Futurismo na última parte, e ainda breves exercícios de "cinéma pur" dispostos ao longo do filme. Comentando este aspecto, Abel faz notar que La Glace "juxtaposes genre to genre, style to style, and class to class, in a multifaceted, Chinese box construction" (Abel 1984: 458-9).

De facto, a caixa chinesa, tal como a figura análoga da boneca russa, revela-se uma metáfora adequada do filme, especialmente ao atentarmos nas diversas histórias integradas nele, que servem também o propósito de chamar a nossa atenção para a montagem (em sentido técnico) e a desmontagem (em sentido hermenêutico). Este aspecto, no entanto, transita do próprio conto de Paul Morand, uma vez que a sua arquitectura textual já se funda no princípio da montagem literária. Ao transpor-se o texto para um novo medium, a montagem torna-se o elemento técnico mais importante do filme.

No capítulo de Esthétique du montage dedicado ao cinema da Primeira Vanguarda Francesa, Vincent Amiel comenta que quando os realizadores franceses estão na sala de montagem, fazem-se acompanhar de uma consciência particular das relações entre a montagem cinematográfica e o fluxo natural do mundo (Amiel 2014: 115). A forma que eles encontram de reproduzir este fluxo não é, no entanto, adoptar uma técnica de montagem transparente, tal como a "montagem invisível" do cinema realista, que André Bazin defenderia nas décadas de 1940 e 1950. Eles acreditam que o fluxo do universo é, na verdade, não linear, porque a experiência do tempo no mundo ocidental moderno é particularmente complexa e enigmática, e de forma alguma clara ou directa. Por conseguinte, o fluxo do filme não deve, também, ser linear. Esta concepção é especialmente verificável no caso de Epstein, uma vez que o cineasta possui um interesse particular pelo 
fenómeno temporal e, sobretudo, pelas relações entre cinema e tempo ${ }^{6}$ La Glace é o primeiro filme em que o realizador materializa o seu interesse pelo tópico, e a narrativa e a montagem são os dois elementos que o auxiliam nesse trabalho.

Epstein escreve dois artigos cuja publicação acompanha o lançamento do filme, e nos quais, no seu estilo caracteristicamente enigmático, chama a atenção do público para estas questões. Em “Temps et personnage du drame", argumenta que a experiência de estar no mundo corresponde à acumulação e à convergência de infinitos momentos - presentes, passados, futuros - , o que torna problemática a própria condição humana, reconfigurando o cogito de Descartes: "[j]e pense donc j'étais", e acrescentando: "Le je futur éclate en je passé; le présent n'est que cette mue instantanée et incessante" (Epstein 1974: 179-80). Esta ideia de um si mesmo que dificilmente resiste intocado à passagem do tempo — com o qual, aliás, está em permanente descoincidência - é metaforicamente figurada em planos de La Glace nos quais o uso das sobreimpressões e de fundidos encadeados sobre a imagem do protagonista, Lui, sublinha a sua natureza desmantelada e fragmentária que a estrutura narrativa, como vimos, só por si já veicula. É devido à possibilidade que oferece de explorar técnicas tais como estas que o cineasta considera que "[l] cinématographe est le seul art qui le puisse représenter tel que ce présent est” (Epstein 1974: 180).

Num outro, e mais célebre, texto, "Art d'événement", Epstein refere-se explicitamente ao novo filme. Ele começa por descrever a cena em que um pássaro embate na cabeça do protagonista no momento em que este conduz furiosamente o seu carro, defendendo depois a ideia de que o "événement" [evento] — uma situação narrativa caracterizada pela fugacidade - deve tornar-se a "dramaturgie nouvelle" do cinema moderno (Epstein 1974: 182). Assim, em La Glace à trois faces, todas as acções (os eventos) seriam subordinadas ao evento final que resulta na morte do homem: "Devant et derrière lui, personnages et actions, soudain, s'ordonnent docilement [...] Les épisodes trouvent chacun leur place, par ordre, déduits, liés, compréhensibles, compris" (Epstein 1974: 182). De forma a compreender a importância deste evento enquanto um princípio estrutural do filme, é vital considerar a sua natureza casual ou acidental. Referindo-se a este acidente na parte final do conto de Morand, Epstein escreve: 
"A arte do evento": acidente, narrativa e forma em La Glace à trois faces, entre Jean Epstein e Paul Morand

Un automobiliste insouciant paraît personnage de peu; une hirondelle volant, de moins encore ; leur rencontre : l'événement. Ce petit point marqué par le bec de l'oiseau sur le front de l'homme avait contre lui la volonté de trois cœurs, la miraculeuse vigilance de l'amour, tous les réflexes de la vie, toutes les probabilités des trois dimensions de l'espace, toute la chance du temps. (Epstein, 1974: 182)

Com uma economia notável, o autor chama a nossa atenção para o acidente (descrevendo-o em termos materiais: "le bec de l'oiseau sur le front de l'homme") como um evento que, através de propriedades específicas (designadamente, o facto de resultar do encontro de contingências temporais e espaciais), coloca em jogo algumas das categorias principais do cinema enquanto meio: narrativa ("l'événement"), espaço ("toutes les probabilités des trois dimensions de l'espace") e tempo ("toute la chance du temps"). 0 acidente, fortuito e aleatório, aparece assim como o evento simbólico que constitui, ele mesmo, a origem da meditação que o filme encerra sobre o cinema.

Este evento em particular distancia-se também de todos os outros eventos que compõem La Glace, no sentido em que ele quebra a tendência para a narração representada pelas histórias contadas pelas três mulheres (as quais, relembro, o espectador vê enquanto "dramatized events" [Fleishman]), ao mesmo tempo que instala definitivamente um princípio de forma no filme: a morte acidental dita o fim da vida do homem em torno do qual este filme se constrói, e, por consequência, também o fim do filme. Podemos supor que, após a morte de "Lui", ele continue a aparecer em histórias "dramatizadas" que outros contam sobre ele; mas, terminando com a sua morte, o filme revela estar menos interessado nas histórias sobre "Lui" do que em "Lui" - personagem elusiva - ele mesmo. Ao passo que, no texto de Morand, tudo é mediado através da linguagem produzida por narradores, Epstein parece dizer-nos que, ainda que experimente efectivamente com as possibilidades narrativas, o filme, enquanto meio de representação, dá prioridade à evidência da matéria (mesmo quando, e especialmente quando, esta matéria é elusiva ${ }^{7}$ ). Deste modo, concretizase uma posição em favor do cinema como um meio não mediado na sua relação com o mundo, por oposição ao código mediado e simbólico da literatura. É pela sua dimensão 
vertiginosa e pela sua inexplicabilidade (ou seja, resistência ao sentido e à linguagem) que o "evento" - e em particular o "acidente" - se adequa com justeza ao cinema, que é o meio por excelência de captar o "nervosismo" do mundo comentado por Epstein em Bonjour cinéma (Epstein 1921: 43-44).

Os dois textos de Epstein permitem-nos compreender a proposta do filme e fazer sentido da sua natureza compósita. Se perspectivarmos La Glace à luz da sugestão de Epstein de que a morte do homem é a situação narrativa fundamental, este evento (e, por metonímia, toda a parte IV, que se intitula justamente "Lui") torna-se o centro em torno do qual todos os outros eventos (e convém lembrar que o filme é pleno de acontecimentos, devido às diversas histórias integradas nele) gravitam, justamente porque é um evento que, contrariamente aos outros que o filme apresenta, resiste à lógica causal da narração. $L a$ Glace torna-se, assim, não um objecto "sem forma" (Audet 2014: 35), composto de elementos diferentes e desconectados, mas um filme muito intencionalmente estruturado, em que cada elemento encontra o seu lugar numa interconectada teia de eventos e de sentidos.

Como avancei antes, as histórias das mulheres servem o propósito de multiplicar a identidade de "Lui", que só pode encontrar alguma espécie de unidade na morte. Este trabalho sobre a narrativa tem implicações determinantes no trabalho sobre a imagem. De alguma forma, o filme antecipa algumas ideias avançadas por Gilles Deleuze no capítulo de Image-Temps dedicado à imagem-cristal. Se atrás me referi aos "filmes dentro do filme" como "dramatizações", segundo Fleishmann (que adopta uma perspectiva mais narratológica, digamos assim), poderia referir-me a essas sequências como "imagens virtuais" de uma "imagem actual" que diz respeito às sequências em que vemos "Lui" a conduzir o automóvel. Contudo, não é absolutamente certo que esta "misteriosa situação", como atrás me reportei a ela, seja uma verdadeira imagem actual em relação à qual as restantes constituem o seu reverso virtual, no estabelecimento de uma "imagem biface", em que actual e virtual "colaescem" (Deleuze 2015: 111). Ou seja, nunca fica inteiramente claro qual é o "circuito" (Deleuze 2015: 110) que se constrói em La Glace à trois faces, no que diz respeito à hierarquia entre as imagens de ordem diversa com as quais ele se constitui. 
"A arte do evento": acidente, narrativa e forma em La Glace à trois faces, entre Jean Epstein e Paul Morand

Na verdade, parecemos estar perante uma obra toda ela localizada no espelho, sem que nos seja permitido o acesso ao que está fora da moldura. Estamos, portanto, no domínio da absoluta virtualidade. Para isto pode chamar-nos a atenção o plano final - que ocorre após o acidente e a aparição de um último intertítulo retirado de Morand ${ }^{8}$ —, em que se vê "Lui" reflectido em três espelhos. Abel é, talvez, o crítico que oferece a interpretação mais convincente destes espelhos como metáfora do filme:

In the final shot of the film, the discourse reinvents and reflects on the schema of the hero's circulation in the narrative. This shot of the three-sided mirror functions metaphorically, in a double operation. As a metaphor of linearity, the hero's image moves forward in the mirror and dissolves away, reenacting his movement from presence to absence in each of the three stories and from life to death in the final story. As a metaphor of simultaneity, however, the mirror itself represents, in paradigm, the three stories narrated by the women. (Abel 1984: 460-1)

Se é verdade que, tal como sugere Abel, este plano pode reportar-se às histórias contadas pelas três mulheres, segundo as quais "Lui" é simultaneamente ele mesmo e um outro (o "Lui" perspectivado por cada uma delas), podemos avançar também agora, aqui chegados, que o mesmo plano parece reportar-se à própria natureza refractada do filme, a esta existência no espelho, um puramente virtual. Este plano final, inteiramente desligado do fluxo da narrativa, fora da temporalidade do filme (cuja linearidade, como vimos, é já de si difícil de circunscrever), é uma imagem-cristal que denuncia a inexistência de uma actualidade das imagens, o que - devo ressalvar - não desqualifica as imagens com as quais o filme se faz. Pelo contrário, reifica-as, na sua virtualidade, como actuais. Trata-se da actualidade do simulacro. Neste sentido, devemos notar que, neste plano, vemos apenas a imagem de "Lui" nos espelhos, estando o seu corpo ausente de campo. Para além disso, e como descreve Abel, os reflexos de "Lui" desmaterializam-se no espelho, salientando a sua vocação para o desaparecimento. É este, na verdade, o caminho que todo o filme prepara. Não havendo corpos (estamos no domínio da virtualidade), há imagem, a qual, ela mesma, também ruma à desaparição. Este é, evidentemente, o movimento de toda a imagem de cinema, fatalmente condenada à duração (ao tempo) da projecção. 
Esta reflexão a propósito da imagem relaciona-se também, directamente, com a montagem do filme e a meditação que esta veicula sobre o tempo: atente-se no momento em que "Lui" morre, no qual há um efeito de sobreimpressão que sugere, por um lado, que ele se desintegra e se perde, mas também, por outro lado, que ele está a adquirir uma nova espécie de unidade ao passar a integrar o mundo natural. Sobre o uso que Epstein faz dos fundidos encadeados e das sobreimpressões, Labourdette escreveu precisamente que "[l]es enchaînements et surimpressions ici mis en œuvre sont un moyen de précipiter le déroulement des événements et donc, en quelque sorte, de dilater le temps tout en dilatant l'espace" (Labourdette 1998: 179, ênfase minha). Seguindo esta ideia, Epstein parece sugerir que, na morte, "Lui" escapa aos grilhões do tempo, do espaço e da percepção humana (e das narrativas humanas), e entra num novo estado da existência ao ingressar na natureza, a qual, por sua vez, não é sujeita ao tempo tal como o compreendemos, e ainda menos ao storytelling; é, pelo contrário, o domínio por excelência dos eventos. ${ }^{9} 0$ acidente — isto é, o único evento do filme alheio à causalidade, à ordem, à lógica — é precisamente o que torna possível atingir este outro estado.

Em jeito de conclusão, ao discutir alguns "filmes episódicos", Siegfried Kracauer escreve que, por vezes, esta tipologia de estrutura "relates in its entirety to the flow of life" (Kracauer 1997: 254), o que é certamente verdade no que diz respeito a algumas obras cinematográficas de propensão coral, tal como, a mero título de exemplo, Amarcord (1973), de Federico Fellini. 0 autor alemão também faz notar que, pelo contrário, outros filmes episódicos acabam por sucumbir ao que entende serem os "dangers of self-containment" (Kracauer 1997: 257), quando, devido a diversos factores, a estrutura segmentada não permite ao filme atingir um todo orgânico.

De acordo com estas duas categorizações, dir-se-ia que La Glace à trois faces reside no meio deste espectro. Num primeiro visionamento, o filme parece algo desarticulado. As marcas evidentes da estrutura quadripartida, em particular, afastam-no decisivamente do "flow of life" que Amarcord, para recuperar o mesmo exemplo, visa reproduzir. Porém, Epstein solicita também uma análise que revela uma meditação convincente (e unificadora, em termos teórico-formais) sobre questões tais como unidade e fragmentação, o tempo e o 
"A arte do evento": acidente, narrativa e forma em La Glace à trois faces, entre Jean Epstein e Paul Morand

ser, arte e vida, que ele pede emprestado a Paul Morand e desenvolve, ampliando-a, no seu próprio filme modernista. Trabalhando claramente com estruturas e formas narrativas complexas, o filme acaba por ensaiar uma subversão da própria lógica da narrativa entendida em sentido clássico, reinstalando uma nova lógica, uma lógica relacionada com "a arte do evento".

\section{NOTAS}

\footnotetext{
${ }^{1}$ Cinco dos filmes de Epstein foram produzidos pela Les Films Jean Epstein. Para além desta trilogia, contamse ainda Mauprat e Au pays de George Sand, em 1926. Devido a problemas financeiros, a companhia é extinta após a produção de La Chute de la maison Usher (cf. o capítulo "Les Films Jean Epstein" da biografia de Epstein escrita por Joël Daire [2014: 79-91])

2 Alguns críticos referem-se ao grupo de cineastas constituído por Epstein, Delluc, Gance et. al. como "Primeira Vanguarda Francesa" (designação que eu adopto aqui, por considerá-la a mais neutra e, ao mesmo tempo, precisa), ao passo que outros usam "Cinema Impressionista" ou "Vanguarda Narrativa Francesa". Richard Abel discute estas terminologias em Abel 1984: 279-282.

3 Malcolm Turvey refere-se a estas cenas como flashbacks (Turvey 2008: 51). Porém, o termo pode ser considerado enganador se tivermos em conta filmes como Das Cabinet des Dr. Caligari, de Robert Wiene (1920), em cujo final o espectador fica a saber que aquilo que tinha testemunhado no curso do filme fora, na verdade, a narrativa contada por um homem psicologicamente instável que toma a sua história por real, ao passo que ela é, evidentemente, uma ficção. Portanto, não obstante parecer estarmos perante flashbacks, este pode não ser o caso - que se prende mais com a transformação de uma narrativa em imagem. Por essa razão,
} 
opto por apropriar-me, nesta discussão de La Glace, dos termos que Avrom Fleishmann propõe a propósito de Caligari: "dramatized narration" (Fleishman 1992: 99).

4 Originalmente em: Jean Epstein (1921), Bonjour cinéma. Paris: Éditions de la Sirène, in (1974) Écrits sur le cinéma, tome I: 1921-1947. Paris: Cinéma Club/Seghers Éditions.

${ }^{5}$ Gostaria de ressalvar, porém, que, não obstante L'Herbier não ter desenvolvido uma reflexão teórica e filosófica com a relevância daquela levada a cabo por Epstein, esta desconsideração da sua obra também não parece ser inteiramente legítima. No capítulo do seu livro El Dorado: Cinema e Modernidade, Fernando Guerreiro caracteriza extensivamente a densidade teórica e conceptual que a obra de L'Herbier possui, a partir da análise do seu filme mais célebre, El Dorado (Guerreiro 2015: 249-284).

6 Cf., em particular, o capítulo "Le temps intemporel", da sua obra de 1946, L'Intelligence d'une machine (Epstein 2014: 39-44), em cuja secção final lemos: “Le cinématographe [...] montre que le temps n'est qu'une perspective de la coexistence des choses. Le temps ne contient rien qu'on puisse appeler temps en soi, pas plus que l'espace ne renferme d'espace en soi" (id:44).

${ }^{7}$ A propósito desta questão, cf. o estudo de Philippe Dubois sobre o motivo figural da tempestade na obra de Epstein, o qual traduz o interesse do cineasta por "tout ce qui relève de l'éclat (de l'éclatement et des éclaboussures) de la matière, et une fascination certaine pour les effets de déstabilisation des formes (fixes)" (Dubois 1998: 269). Este interesse pela tempestade teria por base, e em termos particularmente relevantes no contexto da minha reflexão, "une conception de l'univers basée sur la malléabilité et la transformabilité essentielle des choses, en particulier de et par la perception" (ibid.). Comentando o ensaio de Dubois, Susana Nascimento Duarte sintetiza: "vemos o que o cinema viu e que não éramos capazes de ver - a instabilidade do mundo" (Duarte 2015: 112, ênfase minha).

8 “Ainsi j'appris d'un coup que ces aveux reçus de trois femmes ne cachaient qu'un homme et que cet homme c'était lui".

${ }^{9}$ O animismo filosófico de Epstein, que começaria a ser desenvolvido no filme seguinte, La Chute, e que ocuparia um lugar privilegiado nos filmes filmados na Bretanha, já é, assim, detectável aqui. Sobre este assunto, cf. Moore 2012 e Castro 2016, dois estudos fundamentais que, no entanto, não se debruçam especificamente sobre o estatuto porventura inaugural de La Glace à trois faces nesta problemática.

N. 41 - 12/ 2019 | 13-35 - ISSN 2183-2242 | http:/dx.doi.org/10.21747/21832242/litcomp41a1 


\section{Bibliografia}

Abel, Richard (1984), French Cinema: The First Wave, 1915-1929, Princeton, Nova Jérsia, Princeton University Press.

Aitken, Ian (2001), European Film Theory and Cinema: A Critical Introduction, Edimburgo, Edinburgh University Press.

Amiel, Vincent (2014), Esthétique du montage (3e édition), Paris, Armand Colin.

Audet, René (2014), "To Relate, to Read, to Separate: A Poetics of the Collection and A Poetics of Diffraction", Interférences littéraires/Literaire interferenties, n.o 12, 35-45.

Canudo, Ricciotto (2003), L'Usine aux images, Paris, Séguier.

Castro, Teresa (2016), “Penser le 'cinéma animiste' avec Jean Epstein”, in Jean Epstein : Actualité et postérités, editado por Roxane Hamery e Éric Thouvenel, Rennes, Presses Universitaires de Rennes, 247-260.

Daire, Joël (2014), Jean Epstein : une vie pour le cinéma, Grandvilliers, La Tour Verte.

Duarte, Susana Nascimento (2015), “O poético como manifestação do figural cinematográfico", in A Escrita do Cinema: Ensaios, editado por Clara Rowland e José Bértolo, Lisboa, Documenta, 101-113.

Dubois, Jean (1998), "La tempête et la matière-temps, ou le sublime et le figural dans l'oeuvre de Jean Epstein", in Jean Epstein : Cinéaste, Poète, Philosophe, editado por Jacques Aumont, Paris, Cinémathèque Française, 267-323

Epstein, Jean (2014), "L'Intelligence d'une machine", in L'Intelligence d'une machine, Le Cinéma du diable et autres écrits, Paris, Independencia Éditions, 27-95.

Epstein, Jean (1974), “Temps et personnage du drame" e "Art d'événement", in Écrits sur le cinéma, tome 1 : 1921-1947, Paris, Cinéma Club / Seghers Editions, 177-181 e 181-182. 
Epstein, Jean (1921), Bonjour cinéma, Paris, Editions de la Sirène.

Fleishman, Avrom (1992), Narrated Films: Storytelling Situations in Cinema History, Baltimore e Londres, The Johns Hopkins University Press.

Guerreiro, Fernando (2015), Cinema El Dorado: Cinema e Modernidade. Lisboa: Colibri.

Kracauer, Siegfried (1997), Theory of Film: The Redemption of Physical Reality, Princeton, Nova Jérsia, Princeton University Press.

Labourdette, Régis (1998), "Le temps de quelques analogies dans la Glace à trois faces de Jean Epstein", in Jean Epstein : Cinéaste, Poète, Philosophe, editado por Jacques Aumont, Paris, Cinémathèque Française, 173-203.

Leprohon, Pierre (1964), Jean Epstein, Paris, Seghers Editions.

L'Herbier, Marcel (1998), La Tête qui tourne, Paris, Belfond.

Liebman, Stuart (2012), "Novelty and Poiesis in the Early Writings of Jean Epstein", in Jean Epstein: Critical Essays and New Translations, editado por Sarah Keller e Jason N. Paul, Amesterdão, Amsterdam University Press, 73-91.

Morand, Paul (2000), “La Glace à trois faces”, in L'Europe galante, Paris, Grasset, 9-18.

Moore, Rachel (2012) "A Different Nature", in Jean Epstein: Critical Essays and New Translations, editado por Sarah Keller e Jason N. Paul, Amesterdão, Amsterdam University Press, 177-194.

Rancière, Jacques (2001), La Fable cinématographique, Paris, Editions du Seuil.

Sinnerbrink, Robert (2013), "Early Film-Philosophy: A Dialectical Fable", Screening the Past, n. - 38, <http://www.screeningthepast.com/2013/12/early-film-philosophy-a-dialecticalfable/> (último acesso em 13/05/2019).

Turvey, Malcolm (2008), Doubting Vision: Film and the Revelationist Tradition, Oxford e Nova Iorque, Oxford University Press.

Vernet, Marc (1988), Figures de l'absence : de l'invisible au cinéma, Paris, Editions de l'Etoile. 
Vichi, Laura (2002), Jean Epstein, Milão, Il castoro cinema.

Wall-Romana, Christophe (2013), Jean Epstein: Corporeal Cinema and Film Philosophy, Manchester e Nova Iorque, Manchester University Press.

José Bértolo doutorou-se em 2019, no Programa Internacional em Estudos Comparatistas PhD-Comp (Universidade de Lisboa, Universidade Católica de Lovaina, Universidade de Bolonha), com uma tese sobre as noções de espectralidade e fantasma no cinema português. Enquanto membro do Centro de Estudos Comparatistas da Faculdade de Letras de Lisboa, tem desenvolvido investigação nas áreas dos estudos fílmicos e das relações entre o cinema e outras artes, com especial incidência em questões de ficção e narrativa, representação e figuração, ontologia e materialidade das imagens. Integrou a comissão editorial da revista electrónica Falso Movimento, editou A Escrita do Cinema: Ensaios com Clara Rowland (Documenta, 2015) e Morte e Espectralidade nas Artes e na Literatura com Fernando Guerreiro (Húmus, 2019), e é autor de Imagens em Fuga: Os Fantasmas de François Truffaut (Documenta, 2016) e Sobreimpressões: Leituras de Filmes (Documenta, 2019). 